\section{Daily changes of amino acids in soybean leaflets are modified by $\mathrm{CO}_{2}$ enrichment}

\author{
Richard C. Sicher \\ USDA-ARS, Plant Sciences Institute, \\ Crop Systems and Global Change \\ Laboratory, MD, USA
}

\begin{abstract}
The effects of $\mathrm{CO}_{2}$ enrichment on plant growth and on nitrogen partitioning were examined using soybean [Glycine max (L.) Merr. cv. Clark] leaflets. Plants were grown from single seeds in matching controlled environment chambers. Continuous ambient $\mathrm{CO}_{2}$ partial pressures were from 38 to $40 \mathrm{~Pa}$ and elevated $\mathrm{CO}_{2}$ treatments were 68 to $70 \mathrm{~Pa}$. Total above ground biomass, total leaf area and specific leaf weight of soybean were increased $78 \%, 58 \%$ and $33 \%$, respectively, in response to $\mathrm{CO}_{2}$ enrichment when measured 25 days after sowing. Total chlorophyll (a+b) was 25\% greater in third trifoliolate soybean leaflets in response to $\mathrm{CO}_{2}$ enrichment but total soluble protein did not differ between treatments. These and other measurements indicated that soybean plants were nitrogen sufficient in this study. Variations of total soluble amino acids were observed in soybean leaflets and these were enhanced by $\mathrm{CO}_{2}$ enrichment when measurements were performed mid-day. However, concentrations of total amino acids were similar in both $\mathrm{CO}_{2}$ treatments by end of the photoperiod. Glycine was lower in the elevated compared to the ambient $\mathrm{CO}_{2}$ treatment suggesting that rates of photorespiration were diminished by elevated $\mathrm{CO}_{2}$. Alanine increased $20 \%$ in response to $\mathrm{CO}_{2}$ enrichment. Overall, changes of soluble amino acids in response to $\mathrm{CO}_{2}$ enrichment were smaller than in other crop species and a temporal shift occurred in the daily accumulation of amino acids in soybean leaflets.
\end{abstract}

\section{Introduction}

Photosynthetic capacity frequently decreases when terrestrial plants are grown continuously in $\mathrm{CO}_{2}$ enriched atmospheres. ${ }^{1,2}$ For example, net $\mathrm{CO}_{2}$ assimilation rates, photosynthetic proteins and $\mathrm{Chl}(\mathrm{a}+\mathrm{b})$ of wheat, barley and tobacco leaves decreased in response to elevated $\mathrm{CO}_{2}$ treatments both in season-long field studies and in controlled environments. ${ }^{3-10}$ In contrast to the above photosynthetic pro- teins and in vitro Rubisco activity of soybean leaflets remained largely unaffected by plant growth in elevated $\mathrm{CO}_{2} \cdot{ }^{11-15}$ However, Bernacchi et al. ${ }^{16}$ reported that the photosynthetic rates of soybean leaflets decreased slightly in response to long term $\mathrm{CO}_{2}$ enrichment and Sicher et al. ${ }^{12}$ observed that photosynthetic rates of $\mathrm{CO}_{2}$ enriched soybean plants were approximately $35 \%$ lower than those of plants grown in ambient $\mathrm{CO}_{2}$ when gas exchange measurements were performed at $70 \mathrm{~Pa} \mathrm{CO}_{2}$. Although photosynthetic protein levels were constant, the above evidence suggested that the photosynthetic capacity of soybean decreased in response to elevated $\mathrm{CO}_{2}$ treatments. Therefore, we hypothesized that changes of net $\mathrm{CO}_{2}$ fixation could alter the primary metabolism of soybean leaflets.

Basic biochemical processes that result in photosynthetic acclimation to elevated $\mathrm{CO}_{2}$ are not fully understood, although Geiger et al..$^{9,10}$ demonstrated that high $\mathrm{N}$ fertility partially or even fully reversed the negative effects of $\mathrm{CO}_{2}$ enrichment on leaf proteins of tobacco. Photosynthetic proteins are synthesized from soluble amino acids and these leaf components are sensitive to $\mathrm{N}$ fertility, which in turn can be altered by $\mathrm{CO}_{2}$ enrichment. ${ }^{9,17}$ Understanding the interaction of $\mathrm{CO}_{2}$ enrichment and of soluble amino acid metabolism in soybean could provide valuable information about this crop. Rogers et al. ${ }^{13}$ and Ainsworth et al. ${ }^{14}$ published two years of data on soluble amino acid levels in soybean leaflets grown in the SoyFACE facility at the University of Illinois. Although $\mathrm{CO}_{2}$ effects on soluble amino acids were noted in young leaflets, except for the Gly:Ser ratio, these metabolites were unaffected by $\mathrm{CO}_{2}$ enrichment in mature trifoliolates. These experiments are consistent with what is known about changes of photosynthetic proteins in soybean and the results comprise a valuable dataset. However, the SoyFACE supplemented air with $150 \mu \mathrm{moL} \mathrm{mol}{ }^{-1} \mathrm{CO}_{2}$, which is less than a $50 \%$ increase over current ambient $\mathrm{CO}_{2}$ levels. This is potentially important because effects of elevated $\mathrm{CO}_{2}$ on plant growth and photosynthesis are usually proportional to the change in $\mathrm{CO}_{2}$ concentration. Also, supplemental $\mathrm{CO}_{2}$ was only provided during daylight hours and it is likely that nocturnal $\mathrm{CO}_{2}$ levels alter dark respiration rates and plant growth rates of soybean. ${ }^{18}$ SoyFACE experiments also used ambient temperature and natural sunlight, both of which vary diurnally and during the growing season. Varying environmental conditions can obscure the responses of leaf metabolites to specific treatments. ${ }^{19}$ Therefore, the hypothesis of this study was that soluble amino acid metabolism in soybean leaflets would respond to $\mathrm{CO}_{2}$ enrichment when using twice ambient $\mathrm{CO}_{2}$ partial pressures over the entire light/dark cycle and
Correspondence: Richard C. Sicher, USDA-ARS Plant Sciences Institute, Crop Systems and Global Change Laboratory, Room 342, Building 001, BARC-west, 10300 Baltimore Avenue,

Beltsville, MD, USA 20705.

E-mail: richard.sicher@ars.usda.gov

Key words: photosynthesis, climate change, soluble amino acids, nitrogen metabolism, photosynthate partitioning.

Contributions: the author performed all of this research with contributions from technical support staff.

Conflict of interest: the authors report no conflicts of interest.

Acknowledgments: R.J. Erdman provided technical assistance, C. Chattopodhya helped with the amino acid analysis and J.A. Bunce and B.F. Matthews provided helpful comments on the manuscript

Received for publication: 3 August 2010.

Revision received: 25 October 2010.

Accepted for publication: 16 November 2010 .

This work is licensed under a Creative Commons Attribution 3.0 License (by-nc 3.0).

(C) Copyright R.C. Sicher, 2010

Licensee PAGEPress, Italy

International Journal of Plant Biology 2010; 1:e18 doi:10.4081/pb.2010.e18

constant temperature conditions provided by controlled environment chambers. We observed that a temporal shift in the accumulation of soluble amino acid occurred in soybean leaflets in response to $\mathrm{CO}_{2}$ enrichment.

\section{Materials and Methods}

\section{Plant materials}

Soybean [Glycine max (L.) Merr. cv. Dixon] plants were grown in matching pairs of controlled environment chambers (model M-2, Environmental Growth Chamber Corp., Chagrin Falls, OH, USA) essentially as described previously. ${ }^{11}$ Plants were seeded in $1.8 \mathrm{dm}^{3}$ plastic pots filled with vermiculite, the air temperature was $27 \pm 1^{\circ} \mathrm{C}$ and the PPFD was $850 \pm 40 \mu \mathrm{mol} \mathrm{m}{ }^{-2} \mathrm{~s}^{-1}$. The photoperiod used a $14 \mathrm{~h}$ day/10 $\mathrm{h}$ night cycle and pots were watered once daily with a complete mineral nutrient solution containing $12 \mathrm{mM}$ nitrate and $2.5 \mathrm{mM}$ ammonium. However, 19 d-old or older plants were watered with nutrient solution twice daily to ensure nutrient sufficiency and to avoid drought. Ambient and elevated chamber air $\mathrm{CO}_{2}$ partial pressures were $38 \pm 10$ $\mathrm{Pa}$ and to $70 \pm 10 \mathrm{~Pa}$, respectively. Plant samples 
were harvested 25 DAS. Terminal leaflets of fully-expanded third trifoliolate leaves were excised at indicated times, transferred to paper envelopes and quickly immersed in liquid $\mathrm{N}_{2}$ to quench metabolism. Leaf samples could be stored at $-80^{\circ} \mathrm{C}$ for up to 1 month prior to analysis without altering the results. At each time point five leaves were harvested from plants grown in each $\mathrm{CO}_{2}$ treatment.

\section{Leaf component analysis}

Soluble amino acids were determined as described previously. ${ }^{17}$ Frozen leaf tissue was ground to a fine powder in a mortar and pestle with liquid $\mathrm{N}_{2}$ and $50 \mathrm{mg}$ of the leaf powder was extracted with $70 \%$ methanol in a ground glass tissue homogenizer. Extracts were heated to $45^{\circ} \mathrm{C}$, centrifuged and the supernatants were evaporated to dryness at $37^{\circ} \mathrm{C}$ with a stream of $\mathrm{N}^{2}$ gas. Samples were carefully resuspended in $20 \mathrm{mM}$ HCL and were filtered by centrifugation using a $0.22 \mu \mathrm{m}$ Ultrafree-MC membrane filter unit (Millipore Corp., Bedford, MA, USA). The filtered extracts could be stored at $-20^{\circ} \mathrm{C}$ for up to 1 month prior to chromatography.

Soluble amino acids were determined by an HPLC procedure using the AccQTag pre-column derivatization method (Waters Corp., Milford, MA, USA). Samples and standards were derivatized using an AccQFluor kit from Waters according to the manufacturer's instructions. Separations were performed at $37^{\circ} \mathrm{C}$ on a Waters $600 \mathrm{E}$ Multisolvent Delivery System equipped with a $3.9 \times 150 \mathrm{~mm}$ AccQTag $\mathrm{C}_{18}$ column. Detection was with a Shimadzu 535 fluorimeter (Shimadzu Corp., Columbia MD, USA) with excitation and emission wavelengths of 250 and $395 \mathrm{~nm}$, respectively. The output of the detector was monitored using Empower2 software from Waters. Standard curves were prepared with a known mixture of 19 amino acids for each sample set. The amino acid standards, plus ammonia and the internal standard were separated by over $80 \%$ using the method described above. Plant samples were corrected to $100 \%$ recovery based on the detection of $\alpha$-aminobutyric acid that was added to each extraction.

Other measurements. Various leaf measurements were performed using the same trifoliolate that was used for amino acid analysis and measurement details were essentially as described earlier. ${ }^{17}$ Soluble proteins were extracted in dilute buffer and were determined using Coomassie brilliant blue R-250. Total $\mathrm{Chl}(\mathrm{a}+\mathrm{b})$ was extracted with $80 \%$ acetone and quantified spectrophotometrically. Inorganic $\mathrm{NO}_{3}{ }^{-}$was extracted in $80 \%$ methanol, microfiltered as above, diluted and analyzed by HPLC using a silica based strong anion exchange (SAX) column. For dry weight determinations, shoots were quickly separated into leaves and stems and these were oven-dried for 3 days at $70^{\circ} \mathrm{C}$. Total leaf area was measured with an

Table 1. Effects of $\mathrm{CO}_{2}$ enrichment on leaf $\mathrm{N}$ constituents and on plant growth parameters. Soybean plants grown for 25 days using ambient and elevated $\mathrm{CO}_{2}$ treatments as described under Design and methods. Soluble protein and Chl $(a+b)$ were analyzed using the central lobe of the third trifoliolate leaf of soybean or the most recently collared leaf of wheat. Leaf area and total above ground biomass are for whole plants. Values are means \pm SE for 5 replicate samples. ${ }^{*}$ and ${ }^{* *}$ are for $P \leq 0.05$ and 0.01 , respectively.

\begin{tabular}{lccc} 
Parameter & $36 \mathrm{~Pa} \mathrm{CO}_{2}$ & $70 \mathrm{~Pa} \mathrm{CO}_{2}$ & $\mathrm{P}$ \\
$\mathrm{Chl}(\mathrm{a}+\mathrm{b}), \mathrm{mg} \mathrm{g}^{-1} \mathrm{FW}$ & $1.3 \pm 0.06$ & $1.6 \pm 0.03$ & $*$ \\
Soluble protein, $\mathrm{mg} \mathrm{g}^{-1} \mathrm{FW}$ & $35.9 \pm 1.9$ & $37.2 \pm 2.8$ & $\mathrm{~ns}$ \\
\hline Total leaf area, $\mathrm{m}^{-2}$ & $0.9 \pm 0.03$ & $1.4 \pm 0.02$ & $* *$ \\
Total biomass, $\mathrm{g}$ & $8.1 \pm 0.4$ & $14.4 \pm 0.3$ & $* *$ \\
\hline $\mathrm{SLW}, \mathrm{g} \mathrm{m}^{-2}$ & $3.3 \pm 0.1$ & $3.7 \pm 0.1$ & $* *$ \\
\hline
\end{tabular}

ns, no significant difference.

optical meter from Li-Cor Corp. (model 3100, Lincoln, NE, USA). Specific leaf weight $\left(\mathrm{g} \mathrm{m}^{-2}\right)$ was determined as the ratio of leaf mass per unit leaf area.

\section{Statistical methods}

Results of two completely replicated experiments were combined and significant differences were determined using a two-way Analysis of Variance procedure (StatView, Mountain View, CA, USA). Total soluble amino acid concentrations for a given treatment and time point were determined by summing the concentrations of 17 individual amino acids from each chromatogram.

\section{Results}

\section{Effects of elevated $\mathrm{CO}_{2}$ on soybean growth and $\mathrm{N}$ status}

In the current study soybean plants grown at $70 \mathrm{~Pa} \mathrm{CO}$ were larger on average than the ambient controls (Table 1). When measured 25 DAS total above ground biomass, total leaf area and specific leaf weight (SLW) increased $(\mathrm{P} \leq 0.01)$ by $78 \%, 58 \%$ and $33 \%$, respectively, in the elevated compared to the ambient $\mathrm{CO}_{2}$ treatment. Similar to previous studies ${ }^{11,12}$ soluble protein did not differ among $\mathrm{CO}_{2}$ treatments but $\mathrm{Chl}(\mathrm{a}+\mathrm{b})$ in the 3rd trifoliolate leaflets increased $23 \%$ in response to $\mathrm{CO}_{2}$ enrichment.

\section{Effects of elevated $\mathrm{CO}_{2}$ on nitrate and on total soluble amino acids in soybean leaflets}

Inorganic nitrate concentrations in soybean trifoliolates were between 25 and $40 \mu \mathrm{mol} \mathrm{g}^{-1}$ FW and nitrate was 22\% lower on average $(\mathrm{P}<0.05)$ in the elevated compared to the ambient $\mathrm{CO}_{2}$ treatment (Figure 1A). This difference was observed at all time points during the photoperiod. Total soluble amino acids in the ambient and elevated $\mathrm{CO}_{2}$ treatments were

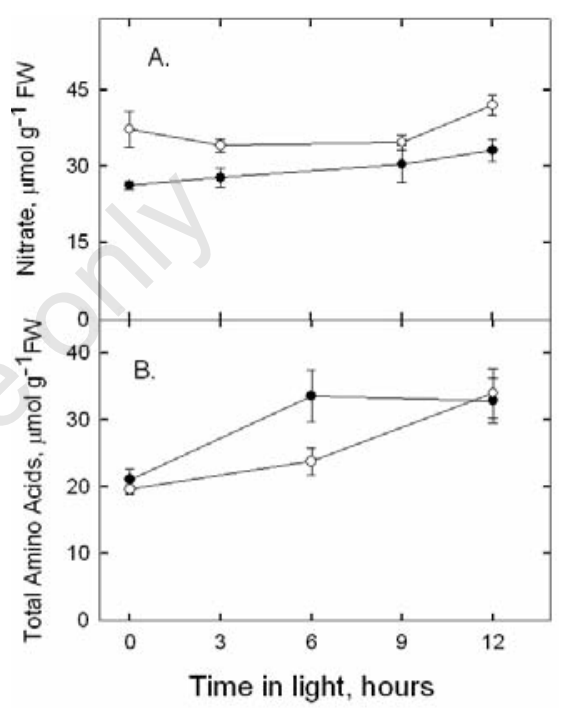

Figure 1. Effects of $\mathrm{CO}_{2}$ enrichment on components of soybean trifoliolates. Inorganic nitrate (panel A) and total soluble amino acids (panel B) were determined at indicated times using the central lobe of the third trifoliolate leaf of 25 day old plants from the ambient $(\circ)$ and the elevated $(\bullet) \mathrm{CO}_{2}$ treatments. Results are means \pm SE for two replicate experiments with five leaflets per time point from each treatment.

similar at 0 -h light (Figure 1B). Over the next $12 \mathrm{~h}$ total soluble amino acids in soybean leaflets increased about $50 \%$ on average in both $\mathrm{CO}_{2}$ treatments. However, almost all of the total soluble amino acid accumulation in the elevated $\mathrm{CO}_{2}$ treatment occurred during the first $6 \mathrm{~h}$ of the photoperiod. In comparison, total soluble amino acids in the ambient $\mathrm{CO}_{2}$ treatment accumulated in nearly linear manner throughout the measurement period

\section{Effects of elevated $\mathrm{CO}_{2}$ on individual soluble amino acids}

Changes of major soluble amino acids in soybean leaflets are shown in Figure 2. The four most abundant soluble amino acids in 
third trifoliolate leaves were Glu, Asn, Asp, and Ser (Figures 2B, 2C, 2D and 2F, respectively) and levels of Asn and Ser accumulated during the light period. In fact, just less than $90 \%$ of the daily increase that was observed for total soluble amino acids from soybean leaflets in the ambient $\mathrm{CO}_{2}$ treatment was attributed to these two individual amino acids. Unlike other species, ${ }^{9,17}$ Gln was present in very low concentrations in soybean leaflets (Figure 2A) when compared to Asn. Glu and Asp were essentially unchanged during the photoperiod when comparing samples from the ambient $\mathrm{CO}_{2}$ treatment. In the elevated $\mathrm{CO}_{2}$ treatment, Glu and Asp levels were low initially, increased about $30 \%$ at mid day and then this was reversed during the second half of the photoperiod. Therefore, changes of Glu and Asp in response to photoperiod and to $\mathrm{CO}_{2}$ enrichment were qualitatively similar in soybean leaflets. Glu and Asn were significantly greater in the elevated compared to the ambient $\mathrm{CO}_{2}$ treatment when comparing measurements for the $6 \mathrm{~h}$ sampling $(\mathrm{P} \leq 0.05)$. Gly was the only major soluble amino acid in soybean leaflets that was lower $(\mathrm{P} \leq 0.05)$ in the elevated than in the ambient $\mathrm{CO}_{2}$ treatment (Figure 1E). Unlike Gly, Ser was unaffected by $\mathrm{CO}_{2}$ enrichment in soybean leaflets $(\mathrm{P}>0.05)$ by. The Gly/Ser ratio was initially about 0.19 in the ambient and elevated $\mathrm{CO}_{2}$ treatments and this ratio decreased with time in the light (Figure 2G). However, the Gly/Ser ratio was not significantly ( $\mathrm{P}>0.05$ ) affected by $\mathrm{CO}_{2}$ enrichment. The Asp/Asn ratio also decreased in both $\mathrm{CO}_{2}$ environments between 0 and $12 \mathrm{~h}$ of light. The Asp/Asn ratio was similar in both $\mathrm{CO}_{2}$ treatments except at $0 \mathrm{~h}$ of the photoperiod.

Minor amino acid levels in soybean leaflets are shown in Figure 3. Ala, Arg, Thr and Phe increased in soybean leaflets du8ring the photoperiod, whereas Pro, Val, Ile and Leu did not. In contrast to the other minor amino acids Ala levels were $29 \%$ greater in leaflets from the elevated compar4d to the ambient $\mathrm{CO}_{2}$ treatment $(\mathrm{P} \leq 0.05)$ in response to $\mathrm{CO}_{2}$ enrichment.

\section{Discussion}

Plants grown in atmospheres enriched with $\mathrm{CO}_{2}$ often display symptoms of $\mathrm{N}$ deficiency. Various leaf properties, including levels of photosynthetic proteins, Rubisco activity, Chl $(a+b)$ and photosynthetic capacity typically decrease and transient starch, the $\mathrm{C} / \mathrm{N}$ ratio and SLW increase in response to $\mathrm{CO}_{2}$ enrichment. ${ }^{20}$ Geiger et al. ${ }^{910}$ demonstrated that the effects of $\mathrm{CO}_{2}$ enrichment on tobacco were essentially eliminated when plants were fertilized with saturating $\mathrm{N}$. Consequently, one likely reason for the acclimation responses of

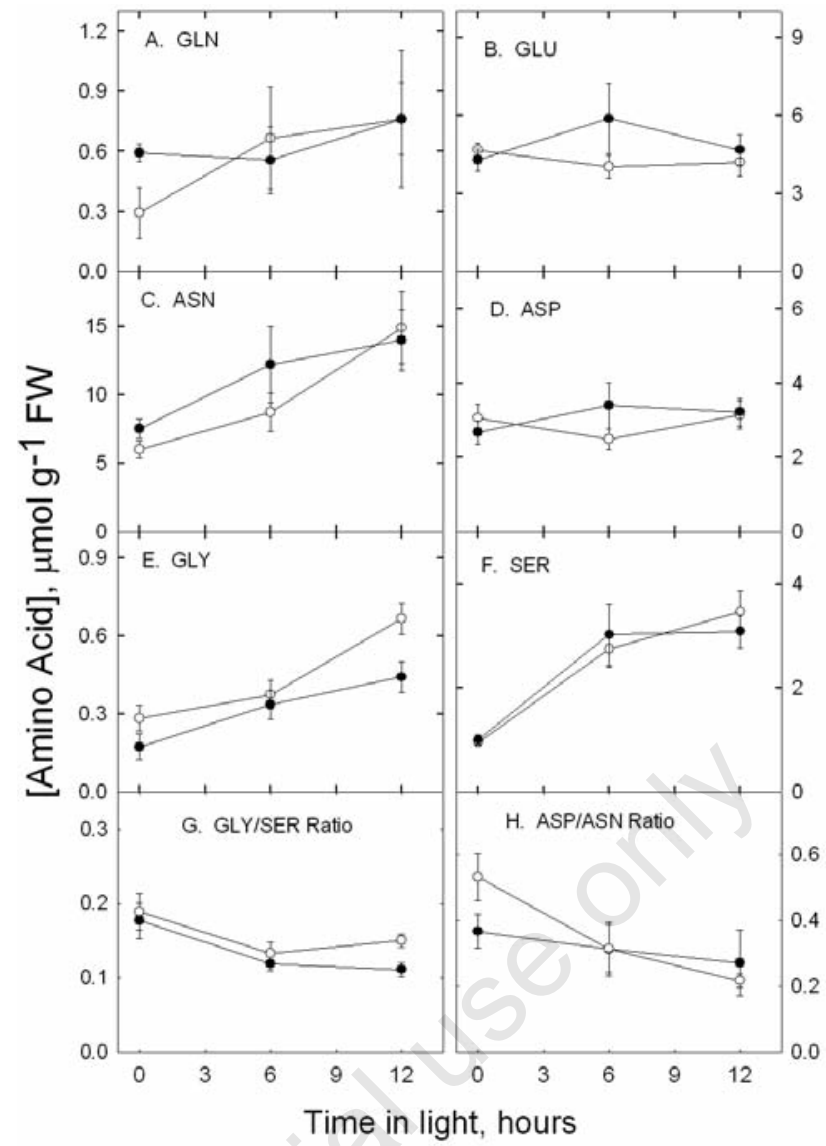

Figure 2. Effects of $\mathrm{CO}_{2}$ enrichment on the accumulation of major soluble amino acids in soybean trifoliolates. Soluble amino acid levels were determined using the central lobe of the third trifoliolate leaf of 25 day old plants from the ambient (O) and the elevated $(\bullet) \mathrm{CO}_{2}$ treatments. Results are means \pm SE for two replicate experiments with five leaflets per time point from each treatment.

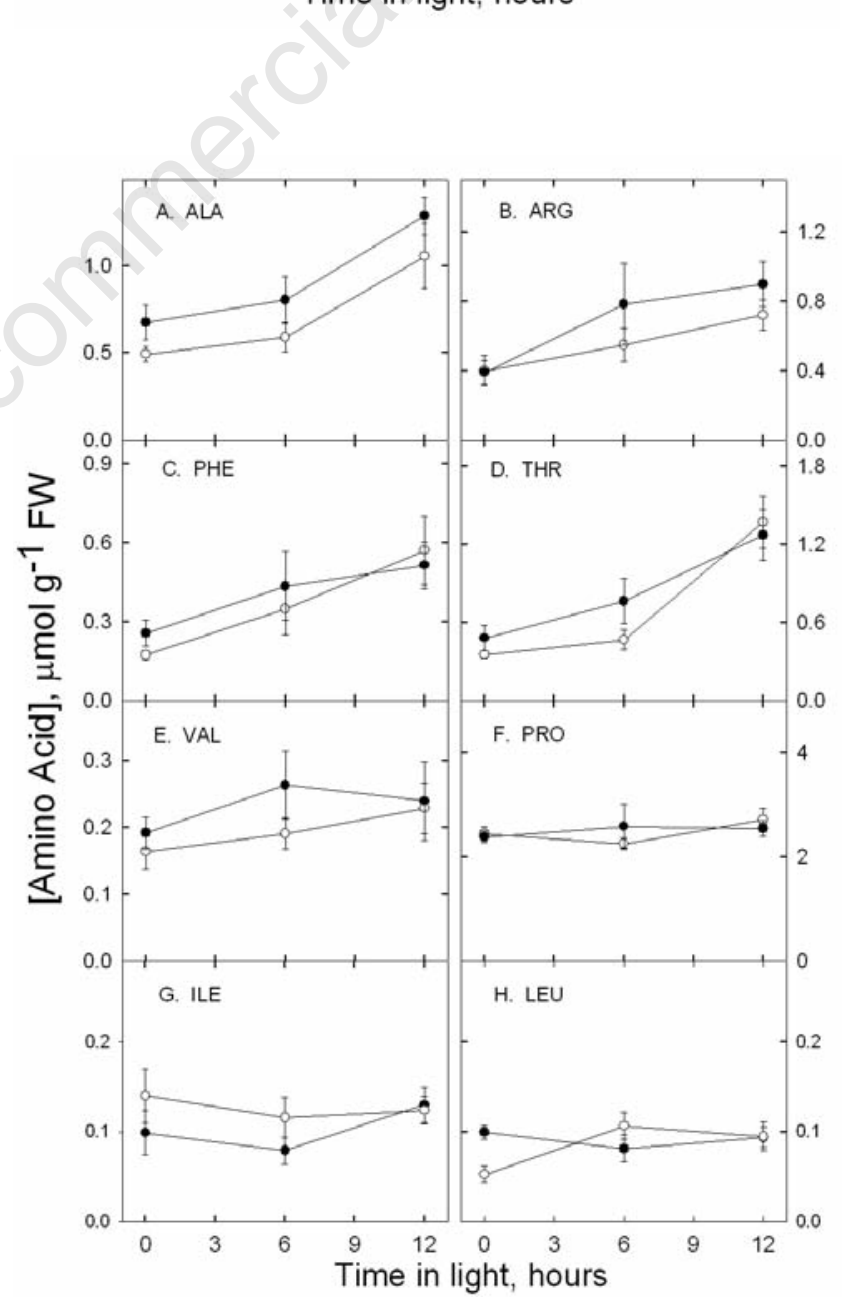

Figure 3. Effects of $\mathrm{CO}_{2}$ enrichment on the accumulation of minor soluble amino acids in wheat leaves. Individual amino acid levels were determined using the most recently expanded leaf of 25 day old plants from the ambient $(\circ)$ and the elevated $(\bullet) \mathrm{CO}_{2}$ treatments. Results are means \pm SE for two replicate experiments with five leaflets per time point from each treatment. 
plants to $\mathrm{CO}_{2}$ enrichment is an acquired $\mathrm{N}$ insufficiency. Effects of $\mathrm{CO}_{2}$ enrichment on leaf properties and on the $\mathrm{N}$ status of soybean are usually much less than that reported for other C3 crop species (i.e., 6, 10). Measurements of soluble protein and $\mathrm{Chl}(\mathrm{a}+$ b) in the present study confirmed these prior observations. It is not obvious why the $\mathrm{N}$ status of soybean was less sensitive to the effects of $\mathrm{CO}_{2}$ enrichment than other species. However, total soluble amino acids in soybean only increased about 50\% during the light period, whereas changes of soluble amino acids in barley, tobacco and wheat increased from 2 to 4 fold. ${ }^{16}$ This implies that amino acid pools in soybean are closer to a metabolic stasis than in other species. Second, the most abundant soluble amino acid in soybean leaflets was Asn and, in the other species mentioned above, Gln was the predominant amino acid.

The finding that soluble protein and $\mathrm{Chl}(\mathrm{a}+\mathrm{b})$ were not decreased by $\mathrm{CO}_{2}$ enrichment suggested that the plants used in this study were $\mathrm{N}$ sufficient. This conclusion was supported by the inorganic nitrate measurements. Inorganic nitrate levels are typically lower in plants grown in elevated compared to ambient $\mathrm{CO}_{2}$ and this may be due to reduced evapotranspiration rates that occur in response to $\mathrm{CO}_{2}$ enrichment. ${ }^{21}$ Under $\mathrm{N}$ insufficient conditions foliar inorganic nitrate levels decreased during the photoperiod. ${ }^{9}$ Because inorganic nitrate concentrations in the present study were constant throughout the day it is unlikely the plants used in this study were $\mathrm{N}$ insufficient. Consequently, $\mathrm{N}$ fertility was not a major factor in determining soluble amino acid concentrations in this study.

In agreement with prior studies ${ }^{13,14}$ the effects of $\mathrm{CO}_{2}$ enrichment on soluble amino acids in soybean leaflets were small. However, in the current study total soluble amino acid levels differed significantly between the elevated and the ambient $\mathrm{CO}_{2}$ treatment when measured at mid-day. This was mostly attributed to Glu and Asn which were greater in the elevated than in the ambient $\mathrm{CO}_{2}$ treatment when comparing measurements performed at mid-day. Note that differences between total soluble amino acids in the ambient and elevated $\mathrm{CO}_{2}$ treatments were not observed at the beginning and end of the photoperiod and the major amino acids Glu, Asp and Ser either showed no net accumulation or a decrease in leaflet concentration during the latter half of the photoperiod. Therefore, a temporal shift in total soluble amino acid accumulation occurred in soybean leaflets in response to $\mathrm{CO}_{2}$ enrichment and the effects of $\mathrm{CO}_{2}$ enrichment on total amino acid levels in soybean leaflets were only observed during the first half of the light period.

Only two individual soluble amino acids, Gly and Ala, differed significantly between $\mathrm{CO}_{2}$ treatments. Gly was $28 \%$ lower in the elevated compared to the ambient $\mathrm{CO}_{2}$ treatment and diminished levels of Gly indicated that $\mathrm{CO}_{2}$ enrichment decreased flux through the photorespiratory pathway. ${ }^{9}$ In contrast to Gly, Ser levels and the Gly/Ser ratio were unaffected by $\mathrm{CO}_{2}$ enrichment in this study. Rogers et al. ${ }^{13}$ reported that Gly and Ser were decreased by $\mathrm{CO}_{2}$ enrichment, although this was only observed on three or four of the six harvest dates performed during the growing season. Along similar lines Ainsworth et al. ${ }^{14}$ reported that the Gly:Ser ratio was the only amino acid parameter affected by $\mathrm{CO}_{2}$ enrichment in soybean leaflets. Taken together the above findings indicated that soybean leaflet amino acids involved in photorespiration were altered by $\mathrm{CO}_{2}$ enrichment. The Asp/Asn ratio decreased in the light phase largely because Asn showed the largest daily variation of any amino acid in soybean leaflets. Ala was increased by $\mathrm{CO}_{2}$ enrichment in soybean leaflets and Ala was one of the more abundant minor amino acids in soybean leaflets. Wallace et al..$^{22}$ suggested that Ala in soybean leaflets was synthesized via the transamination of pyruvate and that Glu was the most likely amino donor. As noted above Glu was elevated by $\mathrm{CO}_{2}$ enrichment when measured at mid-day and this potentially contributed to increased Ala concentrations in soybean leaflets. Ala is transported from soybean leaves in the phloem. Therefore, Ala may contribute additional $\mathrm{C}$ and $\mathrm{N}$ to sink tissues in soybean plants exposed to elevated $\mathrm{CO}_{2}$.

In summary, small but significant changes in soluble amino acid concentrations were identified in $\mathrm{N}$ sufficient soybean leaflets in response to $\mathrm{CO}_{2}$ enrichment. Most importantly total soluble amino acids were greater in the elevated than in the ambient $\mathrm{CO}_{2}$ treatment when measured at mid-day. This was due to a temporal shift in soluble amino acid accumulation in soybean leaflets in response to $\mathrm{CO}_{2}$ enrichment. Mid-day changes in total soluble amino acids resulted primarily from enhanced levels of Asn and Glu in response to $\mathrm{CO}_{2}$ enrichment. In addition Gly was decreased due to a $\mathrm{CO}_{2}$ dependent reduction in photorespiration and Ala increased, possibly because of elevated $\mathrm{CO}_{2}$ effects on the putative amino donor, Glu.

\section{References}

1. Bowes G. Facing the inevitable: plants and increasing atmospheric C02. Annu Rev Plant Physiol Mol Biol 1993;44:309-32.

2. Sage RF. Acclimation of photosynthesis to increasing atmospheric C02: the gas exchange perspective. Photosynth Res
1994;39:351-68.

3. Wong SC. Elevated atmospheric partial pressure of $\mathrm{CO} 2$ and plant growth. I. Interactions of nitrogen nutrition and photosynthetic capacity in C3 and C4 plants. Oecologia 1979;44:68-74.

4. Tuba Z, Szente K and Koch J. The response of photosythesis, stomatal conductance, water-use efficiency and production to long-term elevated $\mathrm{CO}_{2}$. J Plant Physiol 1994;144:661-8.

5. Nie GY, Long SP, Garcia RL, Kimball BA, LaMorte RL, Pinter PJ, Wall GW, Webber AN. Effects of free-air $\mathrm{CO}_{2}$ enrichment on the development of the photosynthetic apparatus in wheat, as indicated by changes in leaf proteins. Plant Cell Environ 1995;18:855-64.

6. Sicher RC, Bunce JA. Relationship of photosynthetic acclimation to changes of Rubisco activity in field-grown winter wheat and barley during growth in elevated carbon dioxide. Photosynth Res 1997;52: 27-38.

7. Sicher RC, Kremer DF, Rodermel SR. Photosynthetic acclimation to elevated CO2 occurs in transformed tobacco with decreased Ribulose 1,5-bisphosphate carboxylase/oxygenase content. Plant Physiol 1994;104:409-15.

8. van Oijen M, Schapendonk AHCM, Jansen $\mathrm{MJH}$, et al. Effects of $\mathrm{CO} 2$ on development and morphology of spring wheat grown in cooled and non-cooled open-top chambers. Aust J Plant Physiol 1998;25:617-626.

9. Geiger M, Walch-Liu P, Engels C, et al. Enhanced carbon dioxide leads to a modified diurnal rhythm of nitrate reductase activity in older plants, and a large stimulation of nitrate reductase activity and higher levels of amino acids in young tobacco plants. Plant Cell Environ 1998;21:253-68.

10. Geiger M, Walch-Liu P, Engels C, et al. The nitrate and ammonium nitrate supply have a major influence on the response of photosynthesis, carbon metabolism, nitrogen metabolism and growth to elevated carbon dioxide in tobacco. Plant Cell Environ 1999;22:1179-99.

11. Campbell WJ, Allen, Jr, LH, Bowes G. Effects of $\mathrm{CO}_{2}$ concentration on rubisco activity, amount and photosynthesis in soybean leaves. Plant Physiol 1988;88: 1310-6.

12. Sicher RC, Kremer DF, Bunce JA. Photosynthetic acclimation and photosynthate partitioning in soybean leaves in response to carbon dioxide enrichment. Photosynth Res 1995;46:409-17.

13. Bunce JA, Sicher RC. Water stress and day-to-day variation in apparent photosynthetic acclimation of field-grown soybeans to elevated carbon dioxide concentration. 
Photosynthetica 2001;39:95-101.

14. Rogers A, Gibon Y, Stitt M, et al. Increased $\mathrm{C}$ availability at elevated carbon dioxide concentration improves $\mathrm{N}$ assimilation in a legume. Plant Cell Environ 2006;29:1651 8.

15. Ainsworth EA, Rogers A, Leakey ADB, et al. Does elevated atmospheric [CO2] alter diurnal $\mathrm{C}$ uptake and the balance of $\mathrm{C}$ and $\mathrm{N}$ metabolites in growing and fully expanding soybean leaves. J Exptl Bot 2007;58: 579-91.

16. Bernacchi CJ, Morgan PB, Ort DR, Long SP The growth of soybean under free air [CO2] enrichment (FACE) stimulates photosynthesis while decreasing in vivo
Rubisco capacity. Planta 2005;220:434-46.

17. Sicher RC, Bunce JA. Growth, photosynthesis,nitrogen partitioning and responses to $\mathrm{CO}_{2}$ enrichment in a barley mutant lacking NADH-dependent nitrate reductase activity. Physiol Plant 2008;134:31-40.

18. Bunce JA. Effects of elevated carbon dioxide concentration in the dark on the growth of soybean seedlings. Ann Bot 1995;75:365-8.

19. Roessner U, Wagner C, Kopka J, et al. Simultaneous analysis of metabolites in potato tuber by gas chromatography-mass spectrometry. Plant J 2000;23:131-42.

20. Stitt M, Krapp A. The interaction between elevated carbon dioxide and nitrogen nutrition: the physiological and molecular background. Plant Cell Environ 1999;22: 583-621.

21. Foyer $\mathrm{CH}$, Lescure J-C, Lefebvre $\mathrm{C}$, et al. (1994) Adaptations of photosynthetic electron transport, carbon assimilation, and carbon partitioning in transgenic Nicotiana plumbaginifolia plants to changes in nitrate reductase activity. Plant Physiol 1994;104:171-8.

22. Wallace W, Secor J, Schrader LE. Rapid accumulation of $\mathrm{Y}$-aminobutyric acid and alanine in soybean leaves in response to an abrupt transfer to lower temperature, darkness or mechanical manipulation. Plant Physiol 1984;75:170-5. 